se divorció siete veces en el término de dos años, pero las autoridades se negaron a concederle la unión por octava vez.

Los divorcios por incompatibilidad de caracteres o por malos tratos vi que eran los más corrientes entre el elemento joven. $\mathbf{Y}$ compulsando las mismas estadísticas, pude enterarme de casos notables. Una mujer, indignada porque su marido no había llegado a casa a almorzar a las dos, corrió a la oficina del registro y pidió el divorcio; el marido llegó tranquilamente a casa a las dos y media, pero su mujer con muy buenas palabras le dijo que nada tenía ya que hacer allí porque había conseguido su divorcio. El marido le suplicó que recapacitase, le expuso los motivos que había tenido para no llegar antes, motivos perfectamente justos, y entonces la mujer, convencida y comprendiendo su precipitación, corrió a las oficinas del Registro y a las tres de la tarde ya estaba casada de nuevo con su mismo marido; de modo que en el intervalo de una hora la mujer había estado caşada, divorciada y vuelta a casar. No cabe mayor expedición.

Contaron al autor de este artículo otro caso no menos gracioso. Dos cónyuges se divorciaron a las tres de la tarde. El marido se fué en busca de otra mujer con la que ya tenía apalabrado su enlace, para proceder a su realización; pero resultó que la mujer aquella, casada, no había tenido tiempo aún de ir a las oficinas del Registro ni era ya hora de tramitar su divorcio hasta el otro día. El aspirante a marido tuvo, pues, que aplazar hasta el día siguiente su nuevo matrimonio y se volvió a la casa de su antigua mujer. $Y$ aquí viene la parte graciosa: la mujer, más lista que él, se había vuelto a casar aquella misma tarde y estaba en casa con su nuevo marido. Por condescendencia tuvo que alojar aquella noche en su antiguo hogar donde mandaba ya otro dueño, que celebraba aquella noche su luna de miel con su divorciada esposa.

Así se estilan las cosas en el paraíso bolchevique, la tierra de los grandes experimentos para la reorganización social. FRAZIER H UN T.

Traducción de $\mathbf{R}$. Mondría.

\title{
Una lectura incitante
}

DICEN que Karl Joris Huysmans, inventor del decadentismo, deleitaba sus ocios leyendo catálogos de librería. Hay otro jardín de incitaciones aun más sugerente, complejo y amplio, porque en sus cuadros no se mueven sombras, como en los libros, sino creaturas vivas; y 
sus pequeños dramas y sus pequeñas comedias no toman existencia de un reflejo, sino directamente de la realidad.

Son los avisos económicos en la última página de los diarios. Los avisos grandes tienen otro carácter. En las líneas donde se paga a tanto la palabra, cada término adquiere peso y significado y se carga de significación. Nadie pone allí un adjetivo sin pensarlo bien, nadie añade un sustantivo sin medir su valor; Flaubert y Jules Renard elaboraban con menos cuidado-y sin tanta ingenuidad-sus frases esculpidas.

Así resultan poemas.

Persona sola, discreta, arrienda departamento a caballero solo....

Véase la penumbra sobre el sexo del arrendador; habrá que deducirlo del que se exige al arrendatario. Y el epíteto discreta, anodino en otra circunstancia ¡cómo cobra relieve en la breve línea, apretada por la tarifa! Las dos «soledades se llaman a distancia, no sin amargura: persona sola. . . caballero solo... . ¿Qué resultaría de su conjunción? Tal vez una perfecta compañía, tal vez una soledad más desolada.

Este otro ya ofrece menos dudas: Joven solo, 28 años, ofrécese acompañar señora sola o caballero.... Aquí conviene mejor no puntualizar demasiado la intención: mira y pasa.... iOh! señora; joh! caballero!

La insolencia plebeya modernista se abre paso, impetuosamente: Chofer competente, toda marca, disponible. Inútil solicitarme por menos $\$ 350$ mensuales. Antes los amos ponian condiciones: 'Inútil presentarse sin buenas referencias.) Ahora son los criados los que exigen. Argumento para Keyserling que levantó al chofer a la categoría de símbolo.

$\mathrm{Y}$ esta desesperada ansia de salir, este grito hacia la aventura, el viaje, lo imprevisto: Joven chileno culiura humanistica ofrécese salir extranjero cualquier parte, cualquier objeto, teniendo especiativas. ¿Espectativas de qué? De ver mundo, de navegar, de tentar suerte en el vasto mundo. Detrás, seguramente, un lector de novelas de viaje. Alli está la cultura humanística, dispuesta a lustrar botas y sacudir vestones con tal de que le compren su dignidad al precio de unos pasajes a tierras desconocidas.

El vocabulario corriente se enriquece en los avisos económicos y halla contracciones inesperadas. Hay que meditar para entender esta palabra: "Luisquincero necesito.... ¿ ¿Luis Quincero? ¿Luis XV? Sí, nada menos; el Rey galante, el monarca bien amado sobrevive en los tacones de los zapatos y en los operarios que los fabrican: si unos se denominan Luis XV, éstos se llamarán, con toda lógica, cluis-quinceros». ¡Milagros 
de la economía! Y restos del prestigio que irradió por el mundo la elegancia de Versalles, el rítmico tacón de la marquesa que bailaba al compás con el marqués. Ellos son los padres de los <Luis-Quinceros.

¿Y esta deliciosa confusión: Casas y juguetes de madera desarmables? Parece una broma; y de ahí viene todo un episodio que conocemos y que tuvo, con ribetes de cómico, su fondo de seriedad. Alguien encargó una de esas casas para un sitio y dió las medidas. Se la hicieron, en el taller, como un juguete; pero, al colocarla, faltó terreno y quedaron piezas sobrantes. Dificultades entre dueño y constructor. - ¿No le gusta la casa?-No, señor.-Pues muy sencillo: me la llevo.-Antes devuélvame Ud. lo pagado de anticipo.-De ningún modo.-Pues, entonces, no se la lleva Ud.- iQue me la llevo!-Veremos.-Viaje a la comisaría y diálogo inaudito:-Señor, quiero que me vigilen la casa tal; quieren llevármela.-El comisario toma nota y pregunta:- ¿Vive alguien ahí?-No, señor. Está vacía.-¿Y qué le quieren llevar?-La casa misma.- ¿La casa? ¿Dice Ud. que le quieren robar la casa?-Justamente: es una casa de madera desarmable....-Gran carcajada policial y detalles innumerables para que entiendan cómo es posible que se quieran llevar no lo que una casa contiene, sino la casa misma. Al fin, ordenan un vigilante de punto fijo y, todas las mañanas, el propietario tiene la fantástica impresión de ir a ver si la casa está todavia en su sitio o si ha desaparecido durante la noche, como los palacios que Aladino edificaba. cCasas y juguetes de madera desarmables.

El genio de las Mil y una noche aparece también en otros avisos, velado de comerciante, como en las calles de Bagdad: Cambio discos viejos por nuevos. . ¿Cuál de esos discos que se buscan encerrará la canción capaz de suscitar al genio maravilloso? Cuidado.

Otras veces una tragedia de familia se abre al público, desgarradora: Deseo noticias de mi madre, Tadea.... O bien: Raúl, vuelve a lu casa, tu padre te perdona.... Niños y perros perdidos, amantes que buscan su ideal, a veces concreto, a veces abstracto, amores sin eco y desesperaciones sin consuelo, ternuras extraviadas que dan ese último paso hacia el azar de la misteriosa publicidad, iqué de novelas comprimidas!

La vida galante asoma de continuo su cabeza disfrazada en los avisos económicos. Se vende, barato, casita bien situada. Parece inofensivo y se escribe. Viene el propietario, explica las condiciones, pondera la situación; al fin, suelta el secreto:Para cgatçonmières no hay cosa mejor,- ¿Sí? ¿Dónde se en- 
cuentra?-En la calle Concepción. ...-¡Oh! señor ¿̨cree Ud. que alguna dama acudirá a una cita en esa calle? ¡De ningún modo!-Fracaso rotundo.

Pero el rey de los avisos económicos, el espléndido, el que abre más vastas perspectivas y tiene más color y hasta perfumes de campo dorado es el que hemos visto por estos días invernales: Se venden las flores de diez mil aromos. Ah! qué magnífico verso modernista : bastaría agregar: «En el paisaje... se venden las flores de diez mil arcmos; y tendríamos unos de esos «aciertos de expresión» que los poetas de la hora actual buscan (y no siempre encuentran) con tanto empeño, y que los críticos benévolos celebran. ¡Se venden las flores de diez mil aromos! Hermosa concisión, sobriedad clásica; el arte moderno lo resume todo. Con esas cuantas palabras, sin nada de más ni de menos, echamos a andar en automóvil una mañana, en alegre compañía, dejamos lejos la ciudad febril y vamos hacia la montaña, hacia la paz transparente de la campiña; delante de nosotros, las copas de los diez mil aromos florecidos levantan sus cúpulas bizantinas y se acercan; es un bosque de cro fino que marea la vista, es la maravilla de la tierra trasmutada por la luz en joyas olorosas y templo de divinidades invisibles. Todo eso, en un segundo, lo tenemos al despertar, en nuestra habitación, junto con la taza del desayuno y la lista de los avisos económicos, que ese anuncio jubilante ilumina de súbito, como una sábana de sol.

No. No hay que reírse de los que leen los avisos económicos de los diarios. Pueden ser viles negociantes que persiguen su interés; pueden ser también poetas y soñadores, novelistas, dramaturgos, hombres de meditación que buscan un modo de escapar a la prisión cotidiana.- - A L O N E.

Nota.-Estas observaciones podrían amplificarse mucho extendiéndolas a los diarios extranjeros. En los de Buenos Aires, por de pronto, llama la atención el ofrecimiento numeroso de ‘mucamos", casi todos «de buena presencia> y algunos «de muy buena presencia?. Es un signo. $-A$.

\section{Una carta sobre d'Halmar}

(2)R. don Raúl Silva Castro. Presente. Estimado Raúl: (5)) Está visto que nunca se le ferdonará a Augusto d'Halmar el haber desertado de las filas de la literatura chilena, para echarse a andar por caminos más dignos de un verdadero artista. Se reconoce en él a un hombre de talento, y en ese ațaque que usted últimamente le ha dedicado, 